Tropical Journal of Pharmaceutical Research January 2018; 17 (1): 47-52

ISSN: $1596-5996$ (print); 1596-9827 (electronic)

(C) Pharmacotherapy Group, Faculty of Pharmacy, University of Benin, Benin City, 300001 Nigeria.

Available online at http://www.tjpr.org

Original Research Article

http://dx.doi.org/10.4314/tjpr.v17i1.8

\title{
Sevoflurane improves gaseous exchange and exerts protective effects in lipopolysaccharide-induced lung injury in mice models
}

\author{
Wei-Min Shen ${ }^{1}$, Chen $\mathrm{Li}^{2}$, Yan-Hua Yuan ${ }^{3}$, Ying-Xue $\mathrm{Xu}^{4}$, Yong-Liang Chi ${ }^{4 \star}$ \\ ${ }^{1}$ Department of Pharmacy, ${ }^{2}$ Department of Spine Surgery, ${ }^{3}$ Department of Well-known Specialist, Shandong Provincial \\ Hospital, ${ }^{4}$ Department of Anesthesiology, The Affiliated Hospital of Shandong Traditional Chinese Medicine University, Jinan \\ City 250014, Shandong Province, China
}

*For correspondence: Email: ADossibehe@yahoo.com; Tel/Fax: 0086-531-68617021

Sent for review: 11 September 2017

Revised accepted: 5 October 2017

\begin{abstract}
Purpose: To investigate the protective effect of sevoflurane against lipopolysaccharide (LPS)-induced acute liver injury (ALI) in amice model.

Methods: Seven week-old female BalB/C mice were used. Lung water content and cell count were estimated by standard protocols. Cytokine and chemokine analysis was performed using commercially available kits. Myeloperoxidase activity was evaluated spectrophotometrically while histopathological analysis was carried out by $H$ and $E$ staining.

Results: The results revealed that sevoflurane treatment significantly improved gaseous exchange, and reduced lung water content and lung inflammation as evidenced by a decrease in neutrophil migration into BALF $(p<0.01)$. Sevoflurane also significantly reversed the LPS-triggered suppression of IL-10 in the lung tissues of LPS-treated mice, when compared to saline-treated controls $(p<0.01)$. It reversed LPS-induced oxidative stress, as demonstrated by increase in total antioxidant capacity (T-AC), catalase (CAT) and superoxide dismutase-1 (SOD-1), as well as an increase in reduced/oxidized glutathione (GSH/GSSG) ratio. In addition, sevoflurane blocked LPS-induced lung tissue injury in ALI mice, and exerted protective effects against acute LPS-induced lung injury.

Conclusion: These results suggest that sevoflurane improves gaseous exchange and exerts a protective effect against LPS-triggered lung injury in mice model, most probably due to its antiinflammatory and antioxidant properties.
\end{abstract}

Keywords: Lung injury, Sevoflurane, Respiratory distress, Superoxide dismutase, Liposaccharide

\begin{abstract}
This is an Open Access article that uses a funding model which does not charge readers or their institutions for access and distributed under the terms of the Creative Commons Attribution License (http://creativecommons.org/licenses/by/4.0) and the Budapest Open Access Initiative (http://www.budapestopenaccessinitiative.org/read), which permit unrestricted use, distribution, and reproduction in any medium, provided the original work is properly credited.
\end{abstract}

Tropical Journal of Pharmaceutical Research is indexed by Science Citation Index (SciSearch), Scopus, International Pharmaceutical Abstract, Chemical Abstracts, Embase, Index Copernicus, EBSCO, African Index Medicus, JournalSeek, Journal Citation Reports/Science Edition, Directory of Open Access Journals (DOAJ), African Journal Online, Bioline International, Open-J-Gate and Pharmacy Abstracts

\section{INTRODUCTION}

Acute lung injury (ALI) and acute respiratory distress syndrome (ARDS1) cases are seen frequently in intensive care units (ICUs) [1]. Although there has been tremendous progress in science and technology, and new therapeutic methods have been introduced, ARDS1associated mortality still remains very high (30 $40 \%$ [1-3]. So far, only low-tidal-volume ventilation has been reported to positively affect mortality in ARDS1. Patients requiring 
mechanical ventilation in ICUs are often administrated intravenous sedatives which include but are not limited to propofol and midazolam [4,5]. However, with recent advancements in science, it has become possible to sedate the patients through volatile anesthesia with the help of Anesthetic Conserving Device [6].

Unlike intravenous sedatives, volatile anesthetics exhibit a number of beneficial effects which improve the health of the patient. Volatile anesthetics have also been reported to exhibit anti-inflammatory activities [6-9]. Sevoflurane, which is one of the commonly used sedatives acts as pre-conditioning as well as postconditioning agent [10] by the protecting organs in ALI models through inhibition of proinflammatory expressions. Moreover, ALI leads to increased accretion of ROS and myeloperoxidase (MPO), and reduces the levels of ROS scavengers such as GSH and superoxide dismutase (SOD), which confer protection against oxidative damage in vivo [11]. Information related to the immune-modulatory activity of volatile anesthetics comes mostly from ischemia-reperfusion injury studies. In the present study, the effect of sevoflurane on gaseous exchange, antioxidant defense system and LPS-induced lung tissue injuries was investigated in a mice model of ALI.

\section{EXPERIMENTAL}

\section{Experimental animals}

Seven week-old female BalB/C mice weighing 21 $\pm 2 \mathrm{~g}$ were used. The mice had free access to pellet diet and drinking water, and were housed in well-ventilated rooms with controlled light/dark cycle, at a temperature of $24 \pm 2^{\circ} \mathrm{C}$ and humidity of $40-62 \%$. The animal protocols for the study were approved by the animal ethical committee of Shandong Provincial Hospital to Shandong University (approval no. SPH-009876/2016/A45), and international guidelines for animal/human studies were followed [12].

\section{Animal grouping and acute lung injury model}

The mice were randomly divided into 5 groups (10 mice / group): group I consisted of normal control mice that were administered normal saline, while group II mice received sevoflurane (300 $\mu \mathrm{L})$ only, dissolved in phosphate-buffered saline (PBS). Group III mice were administered LPS only $(0.5 \mathrm{mg} / \mathrm{kg}$, dissolved in saline); mice in group IV received LPS plus sevoflurane, while group V mice were administered LPS $(0.5 \mathrm{mg} / \mathrm{kg}$ body weight) + dexamethasone ( $5 \mathrm{mg} / \mathrm{kg}$ body weight dissolved in saline). Sevoflurane was given with the aid of AnaCoDa system. The sevoflurane expiratory content was estimated with a multi-gas analyzer and the content of sevoflurane was $1-2 \mathrm{vol} \%$ of the gas.

\section{Lung tissue and BALF extraction}

Extractions of broncho-alveolar lavage fluid (BALF) and lung tissue were carried out as reported earlier [13].The lung tissues were frozen in liquid nitrogen, or fixed in situ at $25 \mathrm{~cm} \mathrm{H}_{2} \mathrm{O}$ with $4 \%$ paraformaldehyde prior to analysis.

\section{Determination of lung water content and cell count}

To determine lung water content, the lung tissues were first weighed and then dried in line with the protocol described previously [14]. The lung water content was calculated as the ratio of $\mathrm{H}_{2} \mathrm{O}$ to body weight. The cell count of the pooled lung lavage fluid was determined by hemocytometer $(n=4)$. Cells in the BALF were pelleted by centrifugation at $1,000 \times \mathrm{g}$ for $15 \mathrm{~min}$, and the protein content of the cell-free BALF was determined by the bicinchoninic acid method. The supernatant samples were used immediately or stored at $-80^{\circ} \mathrm{C}$ for later use.

\section{Cytokine and chemokine analysis}

The levels of IL-6, IL-8 and anti-inflammatory cytokine IL-10 were quantified using commercially available kits according to manufacturer's protocol.

\section{Myeloperoxidase assay}

Myeloperoxidase (MPO) activity was determined to evaluate infiltration of neutrophils in the lung tissues of LPS-induced ALI mouse [15-17]. To assay MPO activity, mice lungs were chopped and then homogenized in PBS containing $0.5 \%$ hexadecyl trimethyl ammonium bromide. The cell homogenate was centrifuged, and the supernatant was added with mixing, to phosphate buffer, $\mathrm{pH} 6.0,0.167 \mathrm{mg} / \mathrm{ml} \mathrm{O-}$ dianisidine hydrochloride and $0.0005 \% \mathrm{H}_{2} \mathrm{O}_{2}$. The absorbance of the resultant solution was read spectrophotometrically at $460 \mathrm{~nm}$. The MPO activity was then determined and expressed as $\mathrm{U} / \mathrm{g}$ as described previously [18].

\section{Antioxidant assays}

Catalase (CAT), SOD, T-AOC and GSH were determined by well-established protocols as reported previously $[19,20]$. 


\section{Histopathological examination}

Lungs were PBS-washed two times and fixed in $4 \%$ paraformaldehyde overnight at $4{ }^{\circ} \mathrm{C}$. Thereafter, the lung tissues were embedded in paraffin and then sectioned. The sectioned tissues were subjected to hematoxylin and eosin (H\&E) staining and examined under a Ti-S bright field microscope [20].

\section{Statistical analysis}

All data are expressed as mean \pm standard error of the mean (SEM). One-way ANOVA followed by Tukey's test were used for statistical analysis with the aid of GraphPad Prism 7 software. The results were considered significant at $p<0.05$ and $p<0.01$.

\section{RESULTS}

\section{Sevoflurane effected gaseous exchange}

LPS administration to rats (group III) caused a significant decrease in $\mathrm{PaO}_{2} / \mathrm{FIO}_{3}$, when compared to normal rats in groups I and II (Figure 1). The LPS + sevoflurane-treated rats (group IV) had a significantly higher $\mathrm{PaO}_{2} / \mathrm{FIO}_{2}$ after $6 \mathrm{~h}$ of LPS injury $(p<0.01)$. However, there were no significant differences between the normal (group I) and sevoflurane-treated (group II) rats.

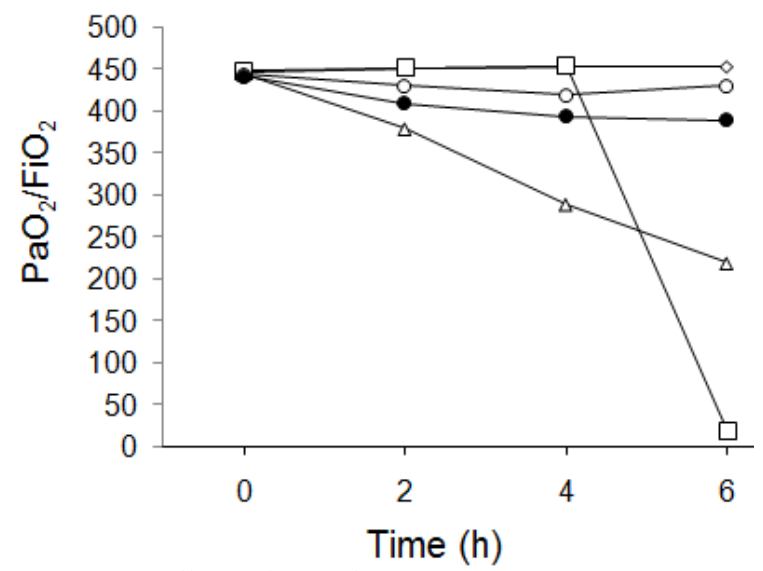

Figure 1: Effect of sevoflurane on gaseous exchange $\mathrm{PaO}_{2} / \mathrm{FiO}_{2}$ in normal or ALI models of mice at indicated intervals of time after sevoflurane administration $(\Delta$ Group I, $\square$ Group II, $\Delta$ Group III, ○ Group IV, • Group V). * $p<0.05$ (group I vs group III); ${ }^{\#} p<0.01$ (group III vs group IV and group V)

\section{Effect of sevoflurane on lung water content}

To evaluate the effect of sevoflurane on lung edema triggered by LPS, the lung water content was measured $24 \mathrm{~h}$ after the intra-nasal administration of LPS (Figure 2). A noticeable rise in water contents of the lungs was observed in group III animals (LPS-treated), relative to group I (saline-treated), and group II mice treated with sevoflurane only. The water contents in the lungs of group IV (LPS + sevoflurane) and group $\mathrm{V}$ (LPS + dexamathasone) were more or less similar, but significantly higher than that of group II animals $(p<0.01)$.

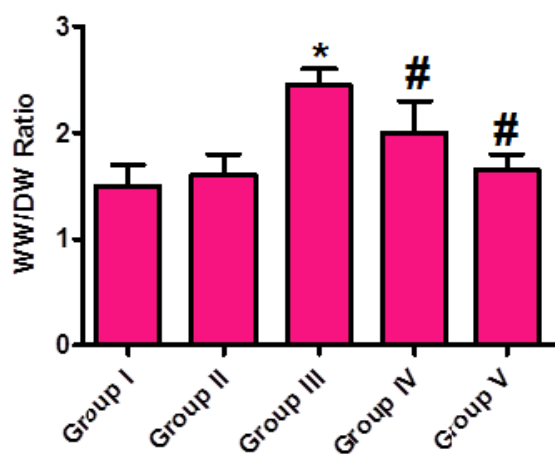

Figure 2: Water content in the lungs of normal or ALI models of mice 24 hours following intra-nasal administration of vehicle or LPS $(n=5)$. Lung tissues were dried by keeping the tissues at $60{ }^{\circ} \mathrm{C}$ for $48 \mathrm{~h}$; ${ }^{*} p$ $<0.05$ (group I vs group III); ${ }^{\#} p<0.01$ (group III vs group IV and group V)

\section{Effect of sevoflurane on lung inflammation and cell count}

Lung inflammation in relation to neutrophil counts triggered by LPS was assessed by determining cell profile of BALF $24 \mathrm{~h}$ succeeding intra-nasal instillation. The LPS treatment caused high escalation in the total cells in group III animals (Figure 3A) and neutrophil counts (Figure 3B), when compared to group I animals. However, total cells (Figure 3A) and neutrophil counts (Figure 3B) in the sevoflurane- treated mice were similar to that of group I animals. In group IV and group $\mathrm{V}$, the cell counts were more or less similar, but significantly lower $(p<0.01)$ than in group II animals (Figure 3A and Figure 3B, respectively).
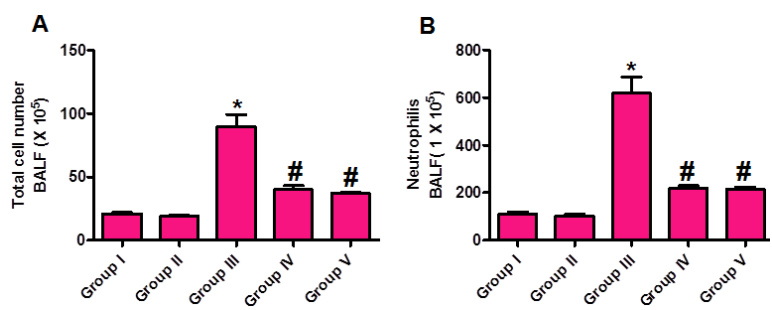

Figure 3: Water content of the lungs of normal or ALI models of mice $24 \mathrm{~h}$ after intra-nasal instillation with LPS. (A) Total cell count of the BALF in normal and ALI mice. Total cell count was determined using the hemocytometer (Invitrogen, Waltham, MA, USA). (B) Neutrophil count in the BALF ( $n=5$ for each group); ${ }^{*} p$ 
$<0.05$ (group I vs group III); \#p $<0.01$ (group III vs group IV and group V)

\section{Sevoflurane altered pro-inflammatory and anti-inflammatory cytokines}

Sevoflurane treatment decreased the LPSinduced high levels of IL-6 and IL-8 in the lungs of the ALI model mice (Figure 4). Furthermore, treatment with LPS significantly $(p<0.05)$ reversed the LPS-triggered suppression of IL-10 in the lung tissues in group III animals, relative to group 1 animals. However, the BALF levels of IL6, IL-8 and IL-10in group IV and group V were almost similar.

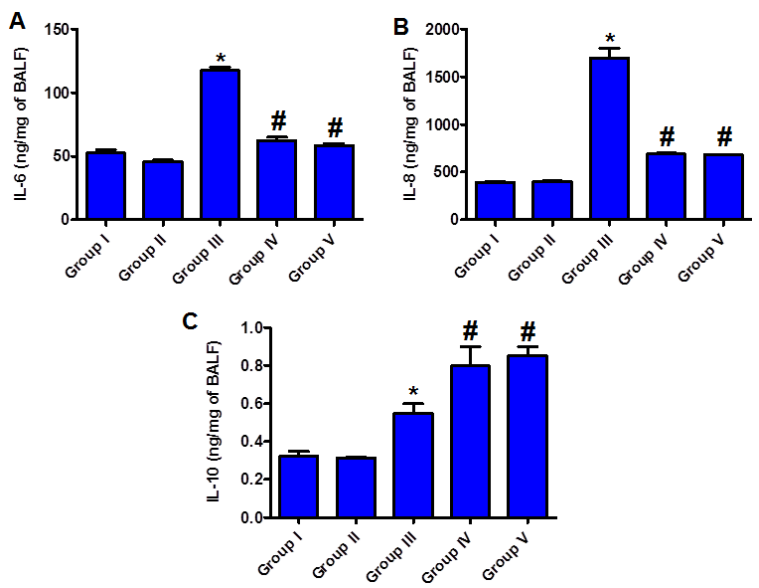

Figure 4: Effect of sevoflurane on pro-inflammatory IL6 and IL-8; and anti-inflammatory IL-10 in lung tissues of ALI mice after 24 hours. Lung levels of IL-6 (A), IL-8 (B), and IL-10 (C); ${ }^{*} p<0.05$ (group I vs group III); ${ }^{*} p<$ 0.01 (group III vs group IV and group V)

\section{Sevoflurane modified myeloperoxidase activity}

Neutrophil infiltration was determined by estimating the MPO activity in homogenized lung tissues of ALI mice (Figure 4). It was observed that LPS increased MPO activity at least 2 folds in group III mice, when compared with group I (saline-treated). However, sevoflurane significantly reduced the MPO activity in group IV mice, when compared with group III (LPStreated) animals. These results suggest that sevoflurane prevents neutrophil migration into the alveolar space.

\section{Sevoflurane reduced oxidative stress}

The effect of sevoflurane on several anti-oxidant biomarkers, such as GSH/GSSG ratio, T-AOC and the activities of CAT and SOD were evaluated. Significant reductions in GSH/GSSG ratio and activities of T-AOC, CAT and SOD were observed in the LPS-treated mice, when compared with group I (saline-treated) control
(Figure 5). Moreover, sevoflurane treatment significantly attenuated the LPS-triggered oxidative stress. However, LPS administration significantly reduced T-AOC (Figure 5B), CAT (Figure $4 C$ ) and SOD (Figure 5D) in lung tissue of ALI mice model, but GSH/GSSG ratio remained unaffected (Figure $5 \mathrm{~A}$ ).

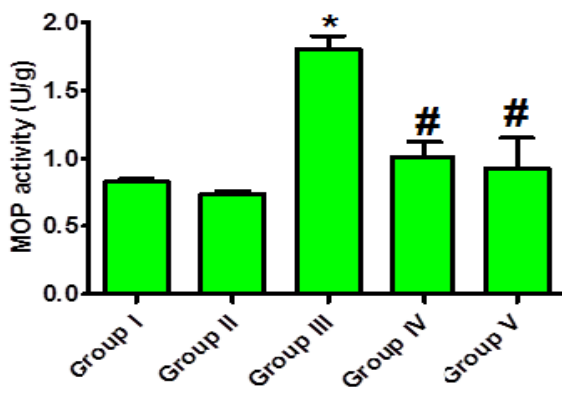

Figure 5: MPO activity in the lung tissues of normal or ALI mice model treated with sevoflurane $(n=5)$; ${ }^{*} p<$ 0.05 (group I vs group III); ${ }^{*} p<0.01$ (group III vs group IV and group V)

\section{Histological features}

The LPS treatment resulted in diffused interstitial edema, alveolar thickening, extensive leukocyte infiltration into the interstitium and alveoli, and a significant reduction in air spaces of alveoli in group III animals (Figure 6A-D). However, treatment with sevoflurane in group IV significantly attenuated these pathological changes in ALI mice when compared to group III (Figure 6E).
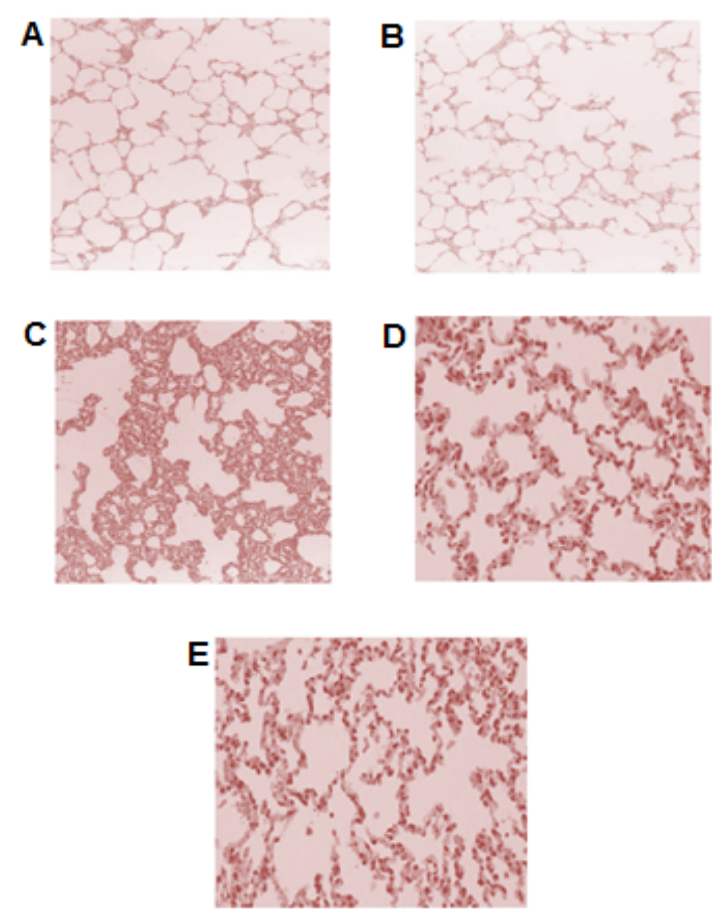

Figure 6: Effect of sevoflurane on histopathological changes in lung tissues in LPS-treated ALI mice. Representative histological changes of lung obtained 
from mice of different groups: Group I (A), Group II (B), Group III (C) Group IV (D) and (E) (H\& E, x 200)

\section{DISCUSSION}

Sevoflurane is one of the commonly used sedatives and acts as pre-conditioning as well as post-conditioning agent by protecting organs in ALI models through inhibition of pro-inflammatory expressions [10]. In the present study, the effects of sevoflurane on gaseous exchange, antioxidant defense system and LPS-induced lung tissue injuries were investigated in a mice model of ALI. The results indicated that sevoflurane significantly improved gaseous exchange, as was evident from $\mathrm{PaO}_{2} / \mathrm{FIO}_{2}$. Lipopolysaccharide (LPS) is often associated with pulmonary edema. Therefore, lung water content was estimated 24 $h$ after the intra-nasal instillation of LPS or saline to mice.

Sevoflurane administration to LPS-treated mice significantly improved water content of the LPStreated mice when compared to the salinetreated control mice, indicating the role of sevoflurane in relieving lung edema. No significant difference in lung water content was seen between groups IV and V animals that were treated with dexamethasone, which suggests that sevoflurane and dexamethasone exert similar protective effects in ALI mice model. Lung edema, and endothelial/epithelial injuries are associated with influx of neutrophils into the interstitium and broncho-alveolar space. Neutrophils have been reported to play important roles in the progression of ALI and ARDS [22]. This is so because stimulation and transmigration of neutrophils are characteristic steps in the development of ALI and ARDS. Thus, the total cell count and number of neutrophils in the BALF of normal and control mice were monitored. The results also indicated that sevoflurane prevented neutrophil migration into the lung alveolar space.

Several laboratory and clinical studies have reported major roles for an intricate set of inflammatory cytokines and chemokines in the initiation of inflammation-triggered ALI from aspiration, sepsis, pneumonia, and shock [23]. The results obtained in the present study revealed that the pro-inflammatory cytokines (IL6 and IL-8) were augmented in the LPS groups when compared to control groups, but IL-10 was reduced. The results also indicated that treatment LPS enhanced the levels of MPO, indicating that inflammation triggered by LPS administration plays a significant role in the pathogenesis of lung injury in mice. Myeloperoxidase (MPO) is a widely used marker for neutrophil activity. Oxidative stress also triggers inflammatory responses which in turn induce the generation of ROS. Oxidative stress and inflammation have been reported to be interconnected events both of which are involved in the pathogenesis of ALI [24].

In earlier studies, it was reported that intra-nasal LPS instillation triggered the release of high levels cytokines, chemokines and ROS, thereby inducing in mice ALI which has similar pathological characteristics with human ALI [25]. Loss of homeostasis between pro-oxidants and antioxidants is often linked to the etiology of oxidative stress [26].

Hence, the current research was also designed to further explore the impact of sevoflurane on several antioxidant biomarkers, such as GSH/GSSG ratio, CAT and SOD. Considerable reduction in the GSH/GSSG ratio, CAT and SOD were seen in LPS-challenged mice, relative to control mice. However, the LPS-triggered reduction in these anti-oxidative biomarkers was significantly diminished by sevoflurane administration.

\section{CONCLUSION}

Administration of sevoflurane to ALI mice confers protection against acute LPS-induced lung injury. This protective effect may be attributed to its potential anti-oxidant and anti-inflammatory properties. Therefore, the results of the present study point to the potential clinical application of sevoflurane in the prevention of ALI.

\section{DECLARATIONS}

\section{Acknowledgement}

This study was supported by Key Project of Shandong Natural Science Foundation (no. ZR2014HZ005)

\section{Conflict of interest}

No conflict of interest is associated with this work.

\section{Contribution of authors}

The authors declare that this work was done by the authors named in this article and all liabilities pertaining to claims relating to the content of this article will be borne by them.

The main experiment was done by Wei-Min Shen under supervision of Yong-Liang Chi. Chen Li did 
statistical analysis and analysed the data with Yan-Hua Yuan, Ying-Xue Xu.

\section{REFERENCES}

1. Rubenfeld GD, Caldwell E, Peabody E, Weaver J, Martin $D P$, Neff $M$, Stern EJ, Hudson LD. Incidence and outcomes of acute lung injury. N Engl J Med 2005; 353: 1685-1693.

2. Ashbaugh DG, Bigelow DB, Petty TL, Levine BE. Acute respiratory distress in adults. Lancet 1967; 2: 319-323.

3. Phua J, Badia JR, Adhikari NK, Friedrich JO, Fowler RA, Singh JM, Scales DC, Stather DR, Li A, Jones A, Gattas $D J$, Hallett $D$, Tomlinson G, Stewart TE, Ferguson ND. Has mortality from acute respiratory distress syndrome decreased over time? A systematic review. Am J Respir Crit Care Med 2009; 179: 220-227.

4. Girard TD, Bernard GR. Mechanical ventilation in ARDS: A state-of-the-art review. Chest 2007; 131: 921-929.

5. Pittet JF, Mackersie RC, Martin TR, Matthay MA. Biological markers of acute lung injury: Prognostic and pathogenetic significance. Am J Respir Crit Care Med 1997; 155: 1187-1205.

6. Belda JF, Soro M, Badenes R, Meiser A, Garcia ML, Aguilar G, Marti FJ. The predictive performance of a pharmacokinetic model for manually adjusted infusion of liquid sevoflurane for use with the AnestheticConserving Device (Ana-ConDa): A clinical study. Anesth Analg 2008; 106: 1207-1214.

7. Suter D, Spahn DR, Blumenthal S, Reyes L, Booy C, Z'Graggen BR, Beck-Schimmer B. The immunomodulatory effect of sevoflurane in endotoxininjured alveolar epithelial cells. Anesth Analg 2007; 104: 638-645.

8. Reutershan J, Chang D, Hayes JK, Ley K. Protective effects of isoflurane pretreatment in endotoxin-induced lung injury. Anesthesiol 2006; 104: 511-517.

9. Beck-Schimmer B, Urech S, De Conno E, Wittlinger M, Puhan M, JochumW, Spahn DR, Clavien PA. A randomized controlled trial on pharmacological preconditioning in liver surgery using a volatile anesthetic. Ann Surg 2008; 248: 909-918.

10. Yue $T$, Roth Z'graggen B, Blumenthal $S$, Neff $S B$, Reyes L, Booy C, Steurer M, Spahn DR, Neff TA, Schmid ER, Beck-Schimmer B. Post conditioning with a volatile anaesthetic in alveolar epithelial cells in vitro. Eur Respir J 2008; 31: 118-125.

11. Kuo MY, Liao MF, Chen FL. Luteolin attenuates the pulmonary inflammatory response involves abilities of antioxidation and inhibition of MAPK and NFKB pathways in mice with endotoxin-induced acute lung injury. Food Chem Toxicol 2011; 49: 2660-6.
12. Touitou Y, Portaluppi F, Smolensky MH, Rensing L. Ethical principles and standards for the conduct of human and animal biological rhythm research. Chronobiol Intr 2004; 21(1): 161-170.

13. Suliman HB, Ryan LK, Bishop L, Folz RJ. Prevention of influenza-induced lung injury in mice overexpressing extracellular superoxide dismutase. Amer J PhysiolLung Cellu Mol Physiol 2001 280(1): L69-L78.

14. Bus JS, Cagen SZ, Olgaard M, Gibson JE. A mechanism of paraquat toxicity in mice and rats. Toxicol Appl Pharmacol 1976; 35(3): 501-513.

15. Hollingsworth JW, Cook DN, Brass DM, Walker JKL, Morgan DL, Foster WM, Schwartz DA. The role of Tolllike receptor 4 in environmental airway injury in mice. Am J Respir Crit Care Med 2004; 170: 126-132.

16. Xiao Q, Dong N, Yao X, Wu D, Lu Y, Mao F, Zhu J, Li J, Huang J, Chen A, Huang L. Bufexamac ameliorates LPS-induced acute lung injury in mice by targeting LTA4H. Sci Rep 2016; 6: 25298.

17. Tsai YF, Yu HP, Chang WY, Liu FC, Huang ZC, Hwang TL. Sirtinol inhibits neutrophil elastase activity and attenuates lipopolysaccharide-mediated acute lung injury in mice. Sci Rep 2015; 5: 8347.

18. Klebanoff SJ. Myeloperoxidase: friend and foe. J Leukoc Biol 2005; 77: 598-625.

19. Baba SA, Malik SA. Determination of total phenolic and flavonoid content, antimicrobial and antioxidant activity of a root extract of Arisaema jacquemontii Blume. $J$ Taibah Univ Sci 2015; 9(4): 449-454.

20. Baba SA, Malik SA. Evaluation of antioxidant and antibacterial activity of methanolic extracts of Gentiana kurroo royle. Saudi J Biol Sci 2014; 21(5): 493-498.

21. Hu J, Zhang Y, Dong L, Wang Z, Chen L, Liang D, Shi D, Shan X, Liang G. Design, Synthesis, and Biological Evaluation of Novel Quinazoline Derivatives as Anti-inflammatory agents against Lipopolysaccharide-induced Acute Lung Injury in Rats. Chem Biol Drug Des 2014; 85: 672-684.

22. Abraham E. Neutrophils and acute lung injury 619. Crit Care Med 2003; 31: S195-S199.

23. Goodman RB, Pugin J, Lee JS, Matthay MA. Cytokinemediated inflammation in acute lung injury. Cytokine Growth Factor Rev 2003; 14: 523-535.

24. Nicholls SJ. The complex intersection of inflammation and oxidation: implications for atheroprotection. J Am Coll Cardiol 2008; 52: 1379-1380.

25. Lee WL, Downey GP. Neutrophil activation and acute lung injury. Curr Opin Crit Care 2001; 7: 1-7.

26. Hakansson HF, Smailagic A, Brunmark C, Miller-Larsson $A$, Lal H: Altered lung function relates to inflammation in an acute LPS mouse model. Pulm Pharmacol Ther 2012; 25: 399-406. 